\title{
Clinical value of transforaminal epidural steroid injection in lumbar radiculopathy
}

\author{
SM Leung *, WW Chau, SW Law, KY Fung
}

\section{A B S T R A C T}

Objectives: To identify the diagnostic, therapeutic, and prognostic values of transforaminal epidural steroid injection as interventional rehabilitation for lumbar radiculopathy.

Design: Case series.

Setting: Regional hospital, Hong Kong.

Patients: A total of 232 Chinese patients with lumbar radiculopathy attributed to disc herniation or spinal stenosis received transforaminal epidural steroid injection between 1 January 2007 and 31 December 2011.

Interventions: Transforaminal epidural steroid injection.

Main outcome measures: Patients' immediate response, response duration, proportion of patients requiring surgery, and risk factors affecting the responses to transforaminal epidural steroid injection for lumbar radiculopathy.

Results: Of the 232 patients, 218 (94.0\%) had a single level of radiculopathy and $14(6.0 \%)$ had multiple levels. L5 was the most commonly affected level. The immediate response rate to transforaminal epidural steroid injection was $80.2 \%$ in 186 patients with clinically diagnosed lumbar radiculopathy and magnetic resonance imaging of the lumbar spine suggesting nerve root compression. Of patients with single-level radiculopathy and multiple-level radiculopathy, 175 (80.3\%) and 11 (78.6\%) expressed an immediate response to transforaminal epidural steroid injection, respectively. The analgesic effect

This article was published on 14 Aug 2015 at www.hkmj.org. lasted for 1 to $<3$ weeks in 35 (15.1\%) patients, for 3 to 12 weeks in 37 (15.9\%) patients, and for more patients, 106 (45.7\%) were offered surgery, with 65 (61.3\%) undergoing operation, and with 42 (64.6\%) requiring spinal fusion in addition to decompression surgery. Symptom chronicity was associated with poor immediate response to transforaminal epidural steroid injection, but not with duration of pain reduction. Poor response to transforaminal epidural steroid injection was not associated with a preceding industrial injury.

Conclusions: The immediate response to transforaminal epidural steroid injection was approximately $80 \%$. Transforaminal epidural steroid injection is a useful diagnostic, prognostic, and shortterm therapeutic tool for lumbar radiculopathy. Although transforaminal epidural steroid injection cannot alter the need for surgery in the long term, it is a reasonably safe procedure to provide short-term pain relief and as a preoperative assessment tool.

Hong Kong Med J 2015;21:394-400

DOI: 10.12809/hkmj144310

\footnotetext{
1,2 SM Leung *, MMed(Pain Mgt)(Syd), FHKAM (Orthopaedic Surgery)

${ }^{3}$ WW Chau, MSc (Epi \& Biostat)

1,2,4 SW Law, MOM, FHKAM (Orthopaedic Surgery)

1,2,4 KY Fung, MB, BS, FHKAM (Orthopaedic Surgery)
}

${ }^{1}$ Department of Orthopaedics and Traumatology, Alice Ho Miu Ling
Nethersole Hospital, Tai Po, Hong Kong
2 Department of Orthopaedic Rehabilitation, Tai Po Hospital, Tai Po, Hong
Kong
${ }^{3}$ Department of Orthopaedics and Traumatology, The Chinese University
of Hong Kong, Shatin, Hong Kong
${ }^{4}$ Department of Orthopaedics and Traumatology, Prince of Wales
Hospital, Shatin, Hong Kong

than 12 weeks in $92(39.7 \%)$ patients. Of the 232 * Corresponding author: Ism457@ha.org.hk

\section{New knowledge added by this study}

- This is the first local study to evaluate the clinical value of transforaminal epidural steroid injection (TFESI) as an alternative to or antecedent procedure for definitive spinal surgery.

Implications for clinical practice or policy

- TFESI is a reasonably safe diagnostic and therapeutic option as interventional rehabilitation for lumbar radiculopathy.

\section{Introduction}

Lumbar radiculopathy can be well-managed conservatively in the primary health care setting, but many patients with persistent disabling radicular pain need attention in a specialty clinic. The majority of patients first attend a public specialty clinic in
Hong Kong with pain chronicity of more than 12 months, as they have had no significant clinical response to conservative management in primary health care, private medical specialists, traditional Chinese medicine, or alternative medicine, and they anticipate a long waiting time in a public hospital. 
Epidural steroid injection is commonly practised by orthopaedic surgeons, neurosurgeons, rehabilitation specialists, pain specialists, and interventional radiologists worldwide. The thresholds for offering epidural steroid injection by clinicians and acceptance by patients are variable, however.

Transforaminal epidural steroid injection (TFESI) is one of the more common approaches of epidural steroid injection, along with the interlaminar and caudal approaches. The technique is target-specific and the best route for delivering medication to the ventral epidural space (Fig 1a) and dorsal root ganglion, ${ }^{1}$ where most pathological changes occur. ${ }^{2,3}$ The least amount of drug with a relatively higher drug concentration is required to reach the primary site of pathology compared with interlaminar and caudal epidural steroid injections. ${ }^{4}$

Transforaminal epidural steroid injection is a useful procedure for lumbar radiculopathy. ${ }^{5}$ The technique provides neural blockade to anaesthetise the target nerve root for diagnostic purposes, and interrupts nociceptive input and self-sustaining activity of the neurons. Steroid provides antiinflammatory effect (inhibition of pro-inflammatory synthesis and release of mediators) and produces longer-term pain relief, primarily for radiculopathy. The prognostic value of TFESI for surgical outcomes has been reported, with better surgical outcome in TFESI responders with chronic lumbar radiculopathy than in non-responders. ${ }^{6}$ The technique, however, does not alter the ultimate need for surgery. ${ }^{7}$

Underlying sepsis, malignant disease, and coagulopathy are considered to be contra-indications for spinal injection. The perceived benefits and threshold of offering TFESI as an adjunct to conservative treatment for patients with lumbar radiculopathy attributed to disc herniation or spinal stenosis are variable among orthopaedic surgeons,

\section{經椎間孔硬膜外類固醇注射術治療腰椎神經根病 變在臨床中的應用價值}

梁少文、周偉宏、羅尚尉、馮貴游

目的：探討以經椎間孔硬膜外類固醇注射術（TFESI）為腰椎神經根 病變患者作介入康復服務的診斷、治療和預後價值。

設計：病例系列。

安排：香港一所分區醫院。

患者：2007年1月 1日至2011年12月31日期間因椎間盤突出或椎管狹 窄, 須接受TFESI的232名腰椎神經根病變患者。

\section{介入治療：TFESI。}

主要結果測量：腰椎神經根病變患者在接受TFESI後的即時療效、療 效持續時間、最終須進行手術的個案比率, 以及影響TFESI療效的危 險因素。

結果：232例中，218例（94.0\%）屬單節段神經根病變，另 14例 (6.0\%) 屬多節段神經根病變。第五腰椎（L5）最受累及。186例 (80.2\%) 臨床診斷為腰椎神經根病變且腰椎磁共振成像顯示神經根 受到壓迫的患者接受TFESI後有即時療效。單節段和多節段神經根病 變的患者中, 分別有175例 (80.3\%) 和11例（78.6\%）在接受TFESI 後有即時療效。可接受止痛效果持續時間的患者比率為： 1 至少於 3 週 的有 $15.1 \%$ （35例）、3至12週的有 $15.9 \%$ （37例）、多於 12 週的有 $39.7 \%$ （92例）。232例中有106例（45.7\%）被建議進行手術治療， 其中65例 $(61.3 \%)$ 最終接受手術治療, 而當中亦有42例 (64.6\%) 須額外進行脊椎融合。慢性痛症患者通常對TFESI即時療效會較差, 但與可接受止痛持續時間沒有相關性。有工傷史患者與對TFESI無即 時療效也沒有相關。

結論：TFESI作即時止痛的成功率約為 $80 \%$, 這技術可作為腰椎神經 根病變的一個有用診斷和預後工具, 也可作為短期的治療方法。雖然 TFESI不能改變腰椎神經根病變患者最終要接受手術的現實, 但它是 一種相對安全的診斷、術前評估和短期減痛的治療方法。

rehabilitation specialists, and pain specialists. The objective of this study was to identify the diagnostic, therapeutic, and prognostic values of TFESI for

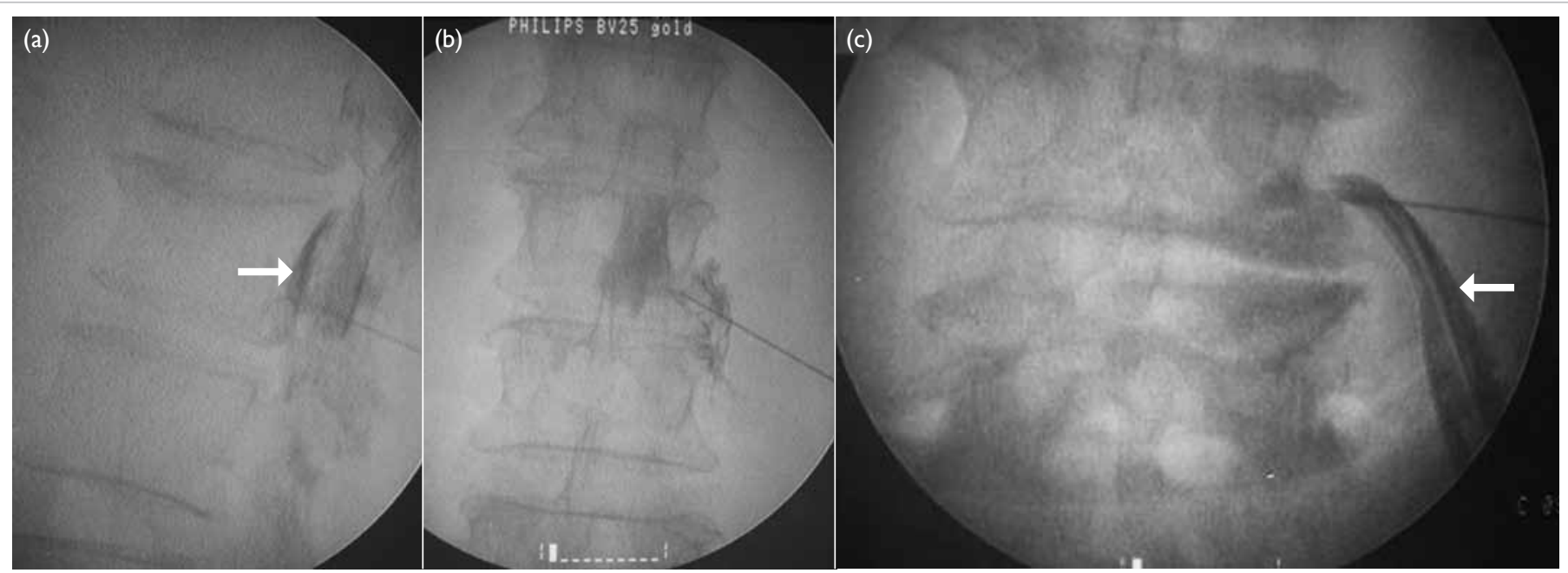

FIG I. Epidural flow of water-soluble non-ionic contrast to reach ventral epidural space as shown in (a) lateral and (b) anteroposterior views; (c) the L4 exiting nerve root is well-outlined by the contrast (arrows) 
lumbar radiculopathy in Chinese patients in Hong Kong.

\section{Methods}

\section{Procedural steps for transforaminal epidural steroid injection}

Patients were placed in the prone position on a radiolucent operating table. A 22-G spinal needle was inserted into the target neuroforamen with fluoroscopic image guidance. The target nerve root and its epidural space were outlined by watersoluble non-ionic contrast, ensuring epidural flow of contrast with no intravascular, intradural, or subcutaneous infiltration (Fig 1). A mixture of 1-mL methylprednisolone acetate $40 \mathrm{mg}$ and $1-\mathrm{mL}$ bupivacaine $0.5 \%$ was injected. Finally, the intact spinal needle was removed.

\section{Data collection and analysis}

All patients who received TFESI for lumbar radiculopathy at Alice Ho Miu Ling Nethersole Hospital, Hong Kong from 1 January 2007 to 31 December 2011 (5 years) were identified by the electronic medical record system in the hospital. Retrospective review of all the medical records identified patients with numeric pain rating scale score (NPRS) of 4 to 7 (out of 10) who took less than three types of analgesics for at least 8 weeks as conservative treatment, or patients with persistent disabling pain with NPRS of $>7$ despite taking more than three types of analgesics for at least 1 week as conservative treatment. Patients with NPRS of $<4$, missing record of post-procedure response, or who had received previous lumbar spinal injection and lumbar spinal surgery were excluded.

The first part of the study assessed the response rate to diagnostic block by the local anaesthetic effect of TFESI for all patients with a clinical diagnosis of lumbar radiculopathy attributed to disc herniation or spinal stenosis, with compatible magnetic resonance imaging (MRI) findings of laterality and affected level. The second part of the study assessed the therapeutic and prognostic values of the steroid effect of TFESI as an adjunct to conservative treatment prior to assessment of surgical need.

The threshold for surgery for patients with lumbar radiculopathy attributed to prolapsed intervertebral disc (PID) and spinal stenosis, in general, considered factors of disabling pain resulting in inability to meet activity demands, clinical MRI findings compatible for laterality and site of compression, and medical fitness for general anaesthesia and major spinal surgery. Spinal fusion might be considered for patients with concomitant spondylolisthesis with instability or anticipated instability resulting from optimal surgical decompression in the lateral recess or foraminal stenosis and concomitant disabling discogenic low back pain that has not responded to conservative treatment.

An immediate response on the procedure day was considered to have a positive diagnostic value. Patients who reported pain reduction of greater than $50 \%$ at the first follow-up visit 4 weeks after TFESI were considered to have a positive therapeutic response to the steroid effects. The response duration, proportion of patients finally requiring surgery, whether decompression alone or spinal fusion besides decompression was needed, and risk factors that affected the response to TFESI were retrospectively reviewed.

Comparisons were carried out for all patients, as well as patients with PID or spinal stenosis only. Associations between responses to TFESI and risk factors for symptom chronicity and industrial injury were done by Fisher's exact test or Mann-Whitney $U$ test where appropriate. Non-parametric tests were done because some continuous variables were not normally distributed. The Statistical Package for the Social Sciences (Windows version 20.0; SPSS Inc, Chicago [IL], US) was used for all statistical analysis. A two-sided $P$ value of $\leq 0.05$ was considered statistically significant.

\section{Results}

A total of 241 patients were recruited into this study. Nine patients were excluded for the following reasons: TFESI responders with PID and L5 radiculopathy had had symptom duration of less than 1 week and TFESI was not considered to be adequate first-line conservative treatment $(n=3)$; and TFESI immediate responders did not return for first follow-up $(n=2)$ and TFESI responses were not documented in the medical records $(n=4)$ so the response durations for these six patients could not be verified. Therefore, the total number of eligible participants was 232 (110 men and 122 women; mean age \pm standard deviation [SD]: $55.6 \pm 14.3$ years). The mean age of patients with PID and spinal stenosis were $37.4 \pm 7.5$ years and $60.3 \pm 11.7$ years, respectively. The symptom chronicity ranged from 8 days to 23 years with a median of 12.0 months, as well as 25 th, 75th, and 90th percentiles being 7.0, 36.0, and 60.0 months, respectively in patients with lumbar radiculopathy. No statistically significant difference $(\mathrm{P}=0.402)$ in symptom chronicity between the PID and spinal stenosis groups was noted (median [interquartile range] duration: PID group 12.0 [8.0-24.0] months vs spinal stenosis group 12.0 [6.0-36.0] months). Fewer PID patients $(n=48 ; 20.7 \%)$ needed TFESI than spinal stenosis patients $(n=184 ; 79.3 \%)$ with lumbar radiculopathy in the study period.

L5 was the most commonly affected level of radiculopathy $(n=150 ; 64.7 \%)$ regardless of whether a patient had single or multiple levels or underlying 
pathology of PID or spinal stenosis (Table 1). Therefore, post-ganglionic block of the L5 nerve root by L5-S1 TFESI was most commonly done.

\section{Diagnostic value of transforaminal epidural steroid injection}

The immediate response rate to TFESI was $80.2 \%$ in 186 patients with clinically diagnosed lumbar radiculopathy and MRI of the lumbar spine suggesting nerve root compression. Overall, 218 $(94.0 \%)$ patients were affected at a single level and $14(6.0 \%)$ were affected at multiple levels (Table 1$)$. The immediate response rates to TFESI were 175 $(80.3 \%)$ in the single-level radiculopathy group and $11(78.6 \%)$ in the multiple-level radiculopathy group. There was no statistically significant difference in the immediate responder rate between patients with PID or spinal stenosis $(\mathrm{P}=0.877)$. No complications were reported.

\section{Predictive value for final need for surgery}

The final need for surgery of TFESI immediate responders was noted in 10/39 (25.6\%) patients in the PID group and $43 / 147$ (29.3\%) patients in the spinal stenosis group (Table 2).
Of the 232 patients, 106 (45.7\%) were offered surgery, of whom 65 (61.3\%) accepted surgery. The mean time from TFESI to uptake of surgery was 7.9 months. There was a statistically significant shorter median time to definitive surgery in the PID group (10.0 months) than in the spinal stenosis group (19.2 months) $[\mathrm{P}<0.01]$. This reflects the fact that PID patients with failed first-line conservative treatment who needed TFESI for lumbar radiculopathy were likely to accept surgery earlier than patients with spinal stenosis. Patients with PID were younger (mean age, 37.0 years) than spinal stenosis patients (mean age, 59.2 years) undergoing surgery, which might be related to less daily activity demand, higher perceived operative risks, and older people being more psychologically reluctant to undergo surgery.

Of the 65 surgical patients, 23 (35.4\%) underwent decompression surgery alone, with a mean time from TFESI of 5.45 months (SD, 5.25 months; median, 3.6 months; range, 8 days to 17.63 months). The remaining 42 (64.6\%) patients required spinal fusion in addition to decompression surgery, with a mean time from TFESI of 9.37 months (SD, 7.23 months; median, 7.22 months; range, 14 days to 25.33 months). The difference in time to surgery for these two groups was statistically significant

TABLE I. Level of radiculopathy

\begin{tabular}{|c|c|c|c|c|}
\hline \multirow[t]{2}{*}{ Level of radiculopathy } & \multicolumn{2}{|c|}{ No. (\%) of patients with radicular symptom } & \multirow{2}{*}{$\begin{array}{c}\text { Total No. (\%) of } \\
\text { patients }\end{array}$} & \multirow[t]{2}{*}{$P$ value } \\
\hline & PID (n=48) & Spinal stenosis $(n=184)$ & & \\
\hline \multicolumn{5}{|l|}{ Single level $(n=218)$} \\
\hline L1 & 0 & 0 & 0 & 0.114 \\
\hline $\mathrm{L} 2$ & 0 & $3(1.6)$ & $3(1.3)$ & \\
\hline L3 & $3(6.3)$ & $11(6.0)$ & $14(6.0)$ & \\
\hline L4 & $3(6.3)$ & $34(18.5)$ & $37(15.9)$ & \\
\hline L5 & $33(68.8)$ & $108(58.7)$ & $141(60.8)$ & \\
\hline S1 & $8(16.7)$ & $15(8.2)$ & $23(9.9)$ & \\
\hline \multicolumn{5}{|l|}{ Multiple levels $(n=14)$} \\
\hline L3, L4 & 0 & $4(2.2)$ & $4(1.7)$ & 0.413 \\
\hline L3, L4, L5 & 0 & $1(0.5)$ & $1(0.4)$ & \\
\hline L3, S1 & 0 & $1(0.5)$ & $1(0.4)$ & \\
\hline L4, L5 & 0 & $5(2.7)$ & $5(2.2)$ & \\
\hline L5, S1 & $1(2.1)$ & $2(1.1)$ & $3(1.3)$ & \\
\hline
\end{tabular}

Abbreviation: PID = prolapsed intervertebral disc

TABLE 2. Proportion of patients requiring surgery in different response and pathology groups $(n=232)$

\begin{tabular}{|c|c|c|c|c|c|}
\hline \multirow[t]{2}{*}{ Type of patients } & \multicolumn{2}{|c|}{ No. $(\%)$ of patients with PID $(n=48)$} & \multicolumn{2}{|c|}{$\begin{array}{l}\text { No. (\%) of patients with spinal } \\
\text { stenosis }(n=184)\end{array}$} & \multirow[t]{2}{*}{$\begin{array}{l}\text { Total No. (\%) of } \\
\text { patients }\end{array}$} \\
\hline & Surgery required & $P$ value & Surgery required & $P$ value & \\
\hline Immediate responders & $10 / 39(25.6)$ & 0.601 & 43/147 (29.3) & 0.481 & $53 / 186(28.5)$ \\
\hline Non-responders & $2 / 9(22.2)$ & & 10/37 (27.0) & & $12 / 46(26.1)$ \\
\hline Total & $12 / 48$ & & $53 / 184$ & & $65 / 232$ \\
\hline
\end{tabular}

Abbreviation: PID = prolapsed intervertebral disc 


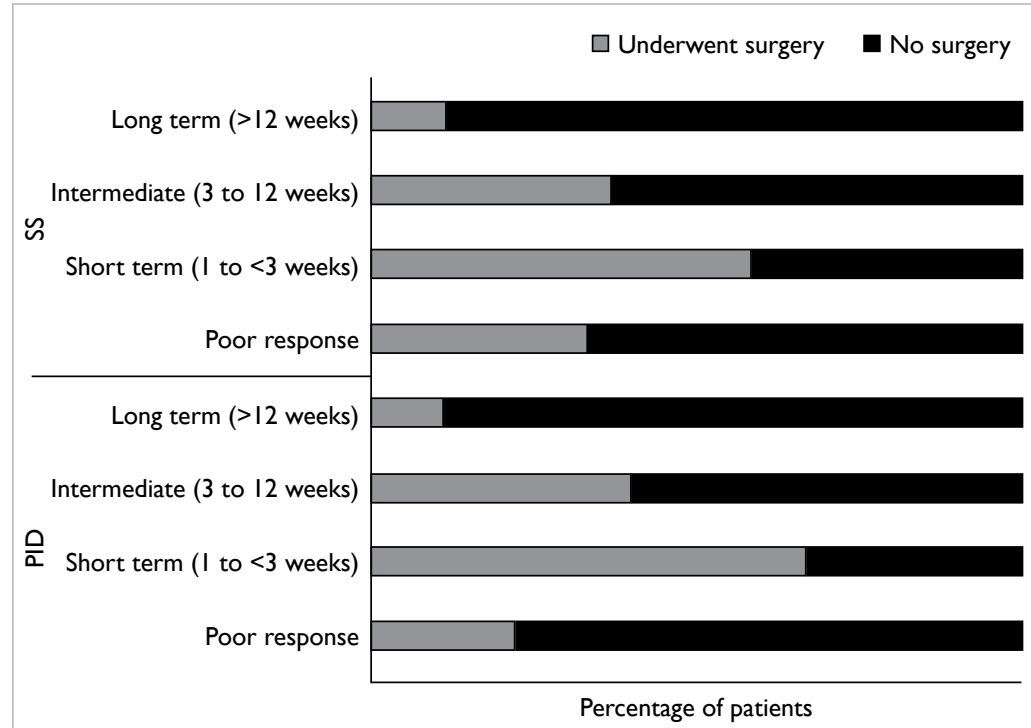

FIG 2. Response duration according to the final surgery rate Abbreviations: PID = prolapsed intervertebral disc; SS = spinal stenosis

$(\mathrm{P}=0.012)$. More patients with a short-term response to TFESI underwent surgery (Fig 2) and TFESI was commonly used as a preoperative assessment tool.

\section{Association between response to transforaminal epidural steroid injection and duration of pain relief}

The analgesic effect of TFESI lasted for less than 1 week (poor response) in $68(29.3 \%)$ patients, for 1 to $<3$ weeks (short term) in $35(15.1 \%)$ patients, for 3 to 12 weeks (intermediate) in $37(15.9 \%)$ patients, and for more than 12 weeks (long term) in 92 (39.7\%) patients. More patients with spinal stenosis underwent surgery in the short-term pain reduction group (1-<3 weeks), and the association between response to TFESI and surgery for spinal stenosis was significant $(\mathrm{P}<0.01)$, but no significance was noted for PID patients $(\mathrm{P}=0.067)$ [Table 3].

\section{Association between poor response to transforaminal epidural steroid injection and chronicity of symptoms and industrial injury}

Poor response (mean, $34.3 \pm 50.9$ months) to TFESI (no immediate response and pain reduction duration of $<1$ week) was significantly associated with chronicity of symptoms (vs $23.1 \pm 28.3$ months in patients with positive response) [ $\mathrm{P}=0.047]$. Pain reduction duration had no significant association with symptom chronicity for pain reduction of less than 3 months and 3 months or more in the PID $(\mathrm{P}=0.225)$ and spinal stenosis $(\mathrm{P}=0.250)$ groups (Table 4).

There was no association between response to TFESI and industrial injury for all eligible patients $(\mathrm{P}=0.138)$ and no significant association according to the underlying cause of PID $(\mathrm{P}=0.359)$ and spinal stenosis $(\mathrm{P}=0.469)$ [Table 5 ].

TABLE 3. Association between response to TFESI, pain relief duration, and final surgery

\begin{tabular}{|c|c|c|c|c|c|c|c|c|c|c|}
\hline \multirow[t]{3}{*}{ Surgery } & \multicolumn{10}{|c|}{ TFESI response duration, No. (\%) of patients } \\
\hline & \multicolumn{5}{|c|}{ PID (n=48) } & \multicolumn{5}{|c|}{ Spinal stenosis $(n=184)$} \\
\hline & Poor ${ }^{*}$ & $\begin{array}{c}\text { Short } \\
\text { term (1-<3 } \\
\text { weeks) }\end{array}$ & $\begin{array}{l}\text { Intermediate } \\
\text { (3-12 weeks) }\end{array}$ & $\begin{array}{l}\text { Long } \\
\text { term (>12 } \\
\text { weeks) }\end{array}$ & $P$ value & Poor* & $\begin{array}{c}\text { Short I } \\
\text { term (1-<3 } \\
\text { weeks) }\end{array}$ & $\begin{array}{l}\text { Intermediate } \\
\text { (3-12 weeks) }\end{array}$ & $\begin{array}{l}\text { Long } \\
\text { term (>12 } \\
\text { weeks) }\end{array}$ & $P$ value \\
\hline No. $(n=167)$ & $13(76.5)$ & $2(33.3)$ & $6(60.0)$ & $15(100.0)$ & 0.067 & $34(66.7)$ & $12(41.4)$ & $17(63.0)$ & $68(88.3)$ & $<0.01$ \\
\hline Decompression only $(n=23)$ & $2(11.8)$ & $2(33.3)$ & $2(20.0)$ & 0 & & $4(7.8)$ & $6(20.7)$ & $4(14.8)$ & $3(3.9)$ & \\
\hline Decompression + fusion $(n=42)$ & $2(11.8)$ & $2(33.3)$ & $2(20.0)$ & 0 & & $13(25.5)$ & $11(37.9)$ & $6(22.2)$ & $6(7.8)$ & \\
\hline Total $(n=232)$ & 17 & 6 & 10 & 15 & & 51 & 29 & 27 & 77 & \\
\hline
\end{tabular}

Abbreviations: PID = prolapsed intervertebral disc;TFESI = transforaminal epidural steroid injection

* Poor response indicates no immediate response to TFESI or limited response with response duration of $<$ I week

TABLE 4. Association between symptom chronicity and TFESI response pattern in PID and spinal stenosis groups

\begin{tabular}{|c|c|c|c|c|c|c|c|c|c|c|}
\hline \multirow{3}{*}{$\begin{array}{l}\text { Symptom } \\
\text { chronicity }\end{array}$} & \multicolumn{10}{|c|}{ TFESI response duration, No. (\%) of patients } \\
\hline & \multicolumn{5}{|c|}{ PID (n=48) } & \multicolumn{5}{|c|}{ Spinal stenosis $(n=184)$} \\
\hline & Poor* & $\begin{array}{l}\text { Short term } \\
(1-<3 \text { weeks })\end{array}$ & $\begin{array}{l}\text { Intermediate } \\
\text { (3-12 weeks) }\end{array}$ & $\begin{array}{l}\text { Long term } \\
\text { (>12 weeks) }\end{array}$ & $P$ value & Poor* & $\begin{array}{l}\text { Short term } \\
(1-<3 \text { weeks) }\end{array}$ & $\begin{array}{l}\text { Intermediate } \\
\text { (3-12 weeks) }\end{array}$ & $\begin{array}{l}\text { Long term } \\
\text { (>12 weeks) }\end{array}$ & $P$ value \\
\hline$<3$ Months & 0 & 0 & $2(20.0)$ & $2(13.3)$ & 0.225 & $4(7.8)$ & $4(13.8)$ & $5(18.5)$ & $16(20.8)$ & 0.250 \\
\hline$\geq 3$ Months & $17(100.0)$ & $6(100.0)$ & $8(80.0)$ & $13(86.7)$ & & 47 (92.2) & 25 (86.2) & $22(81.5)$ & $61(79.2)$ & \\
\hline
\end{tabular}

Abbreviations: PID = prolapsed intervertebral disc;TFESI = transforaminal epidural steroid injection

* Poor response indicates no immediate response to TFESI or limited response with response duration of $<$ I week 
TABLE 5. Association between the response to TFESI and industrial injury

\begin{tabular}{|c|c|c|c|c|c|c|c|c|c|}
\hline \multirow[t]{3}{*}{ Response } & \multicolumn{3}{|c|}{ PID $(n=48)$} & \multicolumn{3}{|c|}{ Spinal stenosis $(n=184)$} & \multicolumn{3}{|c|}{ Total $(n=232)$} \\
\hline & \multicolumn{2}{|c|}{ Industrial injury } & \multirow[t]{2}{*}{$P$ value } & \multicolumn{2}{|c|}{ Industrial injury } & \multirow[t]{2}{*}{$P$ value } & \multicolumn{2}{|c|}{ Industrial injury } & \multirow[t]{2}{*}{$P$ value } \\
\hline & No & Yes & & No & Yes & & No & Yes & \\
\hline Poor response* & $8(28.6)$ & $9(45.0)$ & 0.359 & $40(25.2)$ & $8(32.0)$ & 0.469 & $48(25.7)$ & $17(37.8)$ & 0.138 \\
\hline Positive response & $20(71.4)$ & $11(55.0)$ & & $119(74.8)$ & $17(68.0)$ & & $139(74.3)$ & $28(62.2)$ & \\
\hline
\end{tabular}

Abbreviations: PID = prolapsed intervertebral disc;TFESI = transforaminal epidural steroid injection

* Poor response indicates no immediate response to TFESI or limited response with response duration of $<$ I week

\section{Discussion}

The decision by clinicians to offer a treatment and by patients to accept it is often determined by the perceived benefits, likelihood of success, and the cost (eg risks, time cost, labour cost, and financial cost) of the treatment. In real-world clinical practice, there are large variations in the perceived benefits and likelihood of success of TFESI among clinicians despite its relatively fewer risks and lower cost than spinal surgery. This retrospective case review attempted to show real-life practice in a local unit during a fixed period to evaluate the diagnostic, prognostic, and therapeutic values.

Lumbar radiculopathy can be well managed conservatively, but many patients still have persistent disabling radicular pain needing attention in a specialty clinic. Most patients first attended a public specialty clinic with chronicity of more than 12 months because of no significant clinical response to conservative management. Most patients receiving spinal injection have had a lengthy period of trying various modalities of conservative treatments, reflected by a median time of 12 months of symptom chronicity for patients receiving TFESI.

The threshold of offering TFESI as a diagnostic tool and/or a therapeutic adjunct to conservative treatment is variable among clinicians, reflected by the wide variation of symptom chronicity from 8 days to 23 years among the 232 patients receiving TFESI in this study. Other factors affecting the threshold of offering TFESI include severe neuropathic pain not controlled by more than three kinds of highdose analgesic combinations that act on different pain pathways, and the diagnostic need for doubtful clinical MRI correlations, especially among patients contemplating surgery or who are undergoing a pain relief procedure while waiting for definitive surgery in a local public hospital.

L5 radiculopathy was the most commonly affected level, regardless of whether single or multiple levels were affected, in patients with PID or spinal stenosis in this series. Post-ganglionic block of the L5 nerve root by L5-S1 TFESI was commonly performed.

The clinical presentation of lumbar radiculopathy without significant neurocompression on MRI scan might be related to chemical irritation by local inflammation from an annular tear rather than significant mechanical compression to the nerve root. These patients can be treated conservatively or by TFESI. Sometimes, dynamic spinal stenosis as a result of an incompetent degenerative disc with loss of disc height and its support of the spinal load or spondylolisthesis with spinal instability might be worsened in the upright posture, and might not be well demonstrated in MRI of the lumbar spine taken in the supine position. The technique of TFESI is a target-specific diagnostic tool to the affected nerve root. The procedure increases the diagnostic confidence of clinical lumbar radiculopathy before both the patient and surgeon commit to more invasive surgical interventions, especially for a clinical diagnosis of lumbar radiculopathy with doubtful correlation to MRI findings.

As demonstrated in this study, TFESI is a target-specific diagnostic tool with up to $80 \%$ immediate response for lumbar radiculopathy. An immediate pain response is expected to be related to the local anaesthetic effect acting on the affected nerve root and its dorsal root ganglion, washout effects of injectates on the chemical irritation of the local inflammatory mediators or, occasionally, on the loose extraforaminal sequestrated disc material. The pain reduction duration is expected to be related to the anti-inflammatory effect of steroid. However, it is not expected to change the anatomy, which is due to significant mechanical compression to the affected nerve root. This often needs to be managed surgically so the results of TFESI cannot alter the final need for surgery.

Patients commonly enquire whether TFESI is an alternative or antecedent procedure to definitive spinal surgery. There is strong evidence to support the use of lumbar TFESI in patients with acuteto-subacute unilateral radicular pain caused by herniated nucleus pulposus or spinal stenosis. ${ }^{8,9}$ Nonetheless, there is no relief of pain in patients with chronic failed back surgery syndrome and documented fibrosis of the nerves. ${ }^{2}$

Chronic pain and industrial injury generally have less favourable responses to many treatments. This study showed significant differences in symptom chronicity and poor immediate response 
rate to TFESI $(\mathrm{P}=0.047)$, but failed to show a statistically significant association between symptom chronicity and TFESI response duration in lumbar radiculopathy attributed to $\mathrm{PID}(\mathrm{P}=0.225)$ or spinal stenosis $(\mathrm{P}=0.250)$ [Table 4$]$. The diagnostic value of TFESI is more prominent than the therapeutic value in chronic lumbar radiculopathy in both the PID and spinal stenosis groups. A preceding history of industrial injury was not associated with TFESI response difference in lumbar radiculopathy attributed to PID $(\mathrm{P}=0.359)$ or spinal stenosis $(\mathrm{P}=0.469)$ [Table 5]. Therefore, industrial injury is not a limitation in consideration of offering TFESI.

As demonstrated in this study, most patients (80.2\%) with lumbar radiculopathy attributed to PID or spinal stenosis were managed by nonsurgical treatments. Less than one-half of patients $(45.7 \%, 106 / 232)$ were offered surgery and only $65(61.3 \%)$ of 106 patients accepted surgery. The technique of TFESI is a reasonable therapeutic trial as an alternative procedure, especially in older frail patients with multiple medical co-morbidities and high peri-operative risks. There were no complications related to the injected medication or needle placement in this series. The technique is a reasonable, safe procedure provided that there is radiographic verification of epidural flow of watersoluble non-ionic contrast with no intravascular, intradural, or subcutaneous infiltration. ${ }^{10}$

Nonetheless, there was still a sizable proportion of patients $(45.6 \%)$ who underwent surgery for persistent disabling pain when there was clinical MRI-compatible neurocompression. The mean time to surgery from TFESI was 7.9 months. The technique of TFESI helps give time for better quality of pain relief, but it does not affect the ultimate need of surgery, especially for patients who require spinal fusion for spinal instability, either anticipated preoperatively or after surgical decompression. Among the 186 immediate responders, up to 10 (25.6\%) of 39 in the PID group and 43 (29.3\%) of 147 in the spinal stenosis group required surgery (Table 2). Although TFESI is unable to correct structural pathology, it is a reasonable antecedent procedure to definitive surgical decompression. The technique provides $80.2 \%$ immediate response, thus increasing the diagnostic confidence and providing short-term pain reduction enabling patients to remain active with reduced analgesic consumption and associated systemic side-effects while awaiting definitive spinal surgery. In addition, TFESI provides a better quality of pain relief to help maintain functional independence and to reduce hospital stay. The procedure has a reasonably good diagnostic utility and cost-effectiveness in patients considered for lumbar decompression surgery. ${ }^{11}$

A limitation of this retrospective case review is that the results were based on subjective self- reported pain response, because a more objective functional assessment was not always available in the patients' medical records. A prospective controlled trial is warranted in the future to obtain more comprehensive information about the change in patients' daily function in relation to pain reduction.

\section{Conclusions}

L5 radiculopathy is the most commonly affected level of lumbar radiculopathy. The local anaesthetic effect of TFESI is a useful diagnostic adjunct, with up to $80.2 \%$ immediate response in patients with lumbar radiculopathy. Although TFESI cannot alter the need for spinal surgery, it is a reasonably safe procedure to provide short-term pain relief to allow patients to stay active with reduced analgesic consumption and associated systemic side-effects while awaiting surgery.

\section{Declaration}

The authors do not have any conflicts of interest to declare.

\section{References}

1. Bhargava A, DePalma MJ, Ludwig S, Gelb D, Slipman CW. Injection therapy for lumbar radiculopathy. Curr Opin Orthop 2005;16:152-7.

2. Rho ME, Tang CT. The efficacy of lumbar epidural steroid injections: transforaminal, interlaminar, and caudal approaches. Phys Med Rehabil Clin N Am 2011;22:13948.

3. Roberts ST, Willick SE, Rho ME, Rittenberg JD. Efficacy of lumbosacral transforaminal epidural steroid injections: a systematic review. PM R 2009;1:657-68.

4. Abdi S, Datta S, Trescot AM, et al. Epidural steroids in the management of chronic spinal pain: a systematic review. Pain Physician 2007;10:185-212.

5. Botwin KP, Gruber RD, Bouchlas CG, et al. Fluoroscopically guided lumbar transformational epidural steroid injections in degenerative lumbar stenosis: an outcome study. Am J Phys Med Rehabil 2002;81:898-905.

6. Derby R, Kine G, Saal JA, et al. Response to steroid and duration of radicular pain as predictors of surgical outcome. Spine (Phila Pa 1976) 1992;17(6 Suppl):S176-83.

7. Wilson-MacDonald J, Burt G, Griffin D, Glynn C. Epidural steroid injection for nerve root compression. A randomised, controlled trial. J Bone Joint Surg Br 2005;87:352-5.

8. Karppinen J, Malmivaara A, Kurunlahti $M$, et al. Periradicular infiltration for sciatica: a randomized controlled trial. Spine (Phila Pa 1976) 2001;26:1059-67.

9. Ng L, Chaudhary N, Sell P. The efficacy of corticosteroids in periradicular infiltration for chronic radicular pain: a randomized, double blind, controlled trial. Spine 2005;30:857-62.

10. Ptaszynski A, Huntoon M. Complications of spinal injections. Tech Reg Anesth Pain Manag 2007;11:122-32.

11. Beynon R, Hawkins J, Laing R, Higgins N, Whiting P. The diagnostic utility and cost-effectiveness of selective nerve root blocks in patients considered for lumbar decompression surgery: a systematic review and economic model. Health Technol Assess 2013;17:88. 